\title{
DEVELOPMENT OF HIGHLY HYDROGENATED DLC COATINGS FOR SOLID LUBRICANT APPLICATIONS IN SPACE
}

\author{
A. Vanhulsel ${ }^{(1)}$, F. Velasco ${ }^{(2)}$, R. Jacobs ${ }^{(1)}$, E. W. Roberts ${ }^{(3)}$, I. Sherrington ${ }^{(2)}$, M. J. Anderson ${ }^{(3)}$, L. Gaillard ${ }^{(4)}$ \\ (1) Materials Technology, Vlaamse Instelling voor Technologisch Onderzoek - VITO, Boeretang 200, B-2400 Mol, \\ Belgium \\ (2) Jost Institute for Tribotechnology, University of Central Lancashire, Preston, Lancashire PRI 2HE, UK \\ (3) European Space Tribology Laboratory - ESTL, AEA Technology, Risley, Warrington, Cheshire WA3 6AT, UK \\ (4) European Space Research and Technology Centre - ESTEC, European Space Agency - ESA, Noordwijk, The
} Netherlands

\begin{abstract}
In this paper, the tribological assessment of highly hydrogenated DLC coatings ( 50 at \% hydrogen) is reported. The coatings are deposited by means of a high-density Inductively Coupled Plasma (ICP) source. ICP plasmas combine the advantage of a high throughput (due to high plasma density) with low, controllable ion impact energies on the substrate. The tribological performance of the developed coatings has been assessed by ball-on-disc tests in different atmospheres (air 50\% RH, vacuum and dry nitrogen). In dry and inert environments, the highly hydrogenated DLC coatings reach a very low friction level (0.02-0.03 in dry $\mathrm{N}_{2}, 0.006-0.013$ in vacuum). In humid air conditions, the friction coefficient is increased to 0.20.3 , showing a less stable level. With regard to wear rates, a very low wear factor could be obtained in dry $\mathrm{N}_{2}$ (range E-017 $\mathrm{m}^{3} / \mathrm{Nm}$ ), whereas the highest wear factor was observed in vacuum (range E- $015 \mathrm{~m}^{3} / \mathrm{Nm}$ ).
\end{abstract}

\section{INTRODUCTION}

The development of advanced solid lubricants is of considerable importance to space tribology. The most common solid lubricant coatings today are based on $\mathrm{MoS}_{2}$, lead or PTFE. However, none of these coatings can simultaneously fulfill all specifications, with regard to friction and wear, under ambient atmosphere and in vacuum. Consequently, research is currently being aimed at further improvements in advanced solid lubricant coatings. One approach is to optimize Diamond Like Carbon (DLC) coatings to meet the specifications. DLC are an emerging class of coatings that have shown promising tribological characteristics, including high wear resistance and low friction coefficients, as well as chemical inertness, infrared transparency and high electrical resistivity [1].

Research so far has demonstrated that the hydrogen content of DLC coatings influences the tribological behaviour of the coatings [2] [3]. Incorporating doping elements such as nitrogen, fluorine, silicon and some metals can also be effective [4]. However, few

formulations are capable of offering good tribological performance in both vacuum and ambient environment. In this study, the viability of three formulations of highly hydrogenated DLC coatings $(\sim 50$ at $\%$ hydrogen) for solid lubricant applications in space was assessed by ball-on-disc testing in air, vacuum and dry nitrogen. The best performing coating will be applied to real components in the future and subjected to application-related tests in air and vacuum.

\section{EXPERIMENTAL}

\subsection{Coating deposition}

An appropriate deposition process has been developed to produce highly hydrogenated DLC coatings ( $~ 50$ at $\% \mathrm{H})$ using methane-hydrogen gas mixtures. The coatings are deposited by means of a high-density rf (13.56 MHz) Inductively Coupled Plasma (ICP) process. The substrates are biased by means of a bipolar pulsed dc power, in the frequency range 150$250 \mathrm{kHz}$ using bias voltages of 75-120 V. ICP plasmas combine the advantage of a high throughput (due to high plasma density) with low, controllable ion impact energies on the substrate [5]. The deposition process is fully PACVD-based, which is considered advantageous when compared to the more complex PVD/PACVD hybrid processes.

In this paper, three formulations of the DLC coatings have been evaluated. All coatings were deposited at a process pressure of 10 mTorr, ICP rf power of $100 \mathrm{~W}$, $80 \% \mathrm{CH}_{4}+20 \% \mathrm{H}_{2}$ gas mixture, with different biasing parameters. The coatings were deposited onto AISI 52100 steel discs which were mirror polished $(\mathrm{Ra}<$ $0.01 \mu \mathrm{m})$. Substrate hardness was 62 Rockwell C. Prior to DLC coating deposition, the samples were plasma cleaned and a silicon-based interlayer was applied to ensure coating adhesion. 
As a quality control, the coatings were characterised for coating thickness, roughness, hardness, hydrogen content and adhesion to the steel substrate. An UBM ITF 100 contact stylus profilometer was used to determine the surface roughness and the coating thickness via step height measurement. The mechanical properties (hardness and Young's modulus) were determined by depth sensing indentation, using a Nanotest 550 instrument from Micro Materials Ltd. which was equipped with a Berkovich diamond indenter. Indentation hysteresis curves were analysed according to procedures detailed by Jennett et al. [6]. Penetration depth was limited to $100 \mathrm{~nm}$ to minimise substrate contributions. The hydrogen content of the coatings was determined by Elastic Recoil Detection (ERD) analysis, using $2.02 \mathrm{MeV} \mathrm{He}+$ ions to irradiate the surface. The energy of the recoiling atoms depends on their mass and the recoil angle, enabling their identification and quantification. Determination of the hydrogen content of the DLC coatings, was conducted by the Interuniversity MicroElectronics Center (IMEC), Belgium. The adhesion of the coatings to the substrate was assessed by scratch testing, using a CSM Revetest. In this test, a diamond stylus is drawn across a surface under increasing normal load until some well defined failure event is observed along the scratch track. The normal load at which this occurs is the critical load, measured in Newton (N).

\subsection{Ball-on-disc tribological testing}

Ball-on-disc tests were performed to assess the tribological behaviour of the DLC coatings. Uncoated steel (AISI 52100) balls $\varnothing 7.14 \mathrm{~mm}$ were used as the counterbody. The tests were carried out at a normal force of $5 \mathrm{~N}$ and the wear track radius was set to 9.5 $\mathrm{mm}$. All tests commenced at a sliding speed of $10 \mathrm{rpm}$ $(0.01 \mathrm{~m} / \mathrm{s})$ for the first 100 disc cycles. After this running-in period, sliding speed was set to $200 \mathrm{rpm}$ $(0.2 \mathrm{~m} / \mathrm{s})$ until completion of 100000 disc cycles. The tests in vacuum were stopped when the peak friction coefficient exceeded 0.3 . No additional lubrication was applied to the contact. The coatings were evaluated under vacuum, moist air (50\% RH) and dry nitrogen environments.

Testing in vacuum was carried out using a Pin-On-Disc (POD) tribometer at the European Space Tribology Laboratory (ESTL). This apparatus allows the measurement of sliding friction between a steel ball mounted on a rotating arm loaded against a stationary disc. The test rig is mounted inside a vacuum chamber that is evacuated by a turbomolecular pump down to $5 \times 10^{-6}$ mbar.
The tests in moist air and dry nitrogen were performed at Vito using a CSM BOD Tribometer. This apparatus consists of a rotating disc, while the ball was fixed and loaded by a dead weight system. The humidity of the air was $50 \pm 10 \% \mathrm{RH}$, and dry nitrogen conditions were established by purging the tribometer enclosure with bottled nitrogen $\left(<3 \mathrm{ppm} \mathrm{O}_{2},<2 \mathrm{ppm} \mathrm{H}_{2} \mathrm{O}\right)$.

After test completion, the disc wear factor $\left(\mathrm{k}_{\mathrm{v}}\right)$, i.e. the ratio of the worn volume to the normal load and sliding distance, was obtained by measurements of the depth of the wear scar at four positions 90 degrees apart by surface profilometry. The wear scar on the ball was also measured. The respective wear tracks and scars were inspected using optical microscopy and selected specimens were examined by scanning electron microscopy (SEM).

\section{RESULTS AND DISCUSSION}

\subsection{Coating quality assessment}

Table 1 below shows the quality control results for the different coating formulations. Critical load values correspond with local coating spallation, both cohesive and interfacial. This failure event occurred inside the scratch track (coating formulations 1 and 2) or at the scratch track borders (coating formulation 3).

\subsection{Ball-on-disc tribotest results}

\subsubsection{Effect of test environment}

Figure 1 shows the evolution of the coefficient of friction $(\mu)$ versus sliding cycles for all three coating formulations as obtained from the ball-on-disc tests in humid air and vacuum.

All three coating formulations have a lifetime of over 100000 cycles in air. For coating formulations 1 and 2, the coefficient of friction varies considerably during the test, showing a final friction value of around 0.2. The fluctuation of the friction coefficient could be associated either with a periodical removal and recovery of a transfer layer built up at the surface of the ball, or with the abundance of wear debris in the contact. However, microscopic inspection of the wear tracks after the tests showed relatively low amounts of debris on the wear tracks, suggesting that fluctuations are probably not associated with debris. Coating formulation 3 shows a stable friction level around 0.17 throughout the test. A steady state friction level was reached after 40000,10000 and 1000 cycles for coating formulation 1, 2 and 3, respectively. For all three coating formulations, wear track depth never exceeded $0.6 \mu \mathrm{m}$, which constitutes about half the total coating thickness. 
Table 1. Quality control parameters of the different DLC coating formulations

\begin{tabular}{ccccccc}
\hline $\begin{array}{c}\text { Coating } \\
\text { formulation }\end{array}$ & Thickness $(\mu \mathrm{m})$ & $\begin{array}{c}\text { Roughness } \\
\mathrm{R}_{\mathrm{a}}(\mu \mathrm{m})\end{array}$ & Hardness $(\mathrm{GPa})$ & E-modulus (GPa) & Critical load (N) & H-content $(\%)$ \\
\hline 1 & 1.1 & 0.01 & $8.7 \pm 0.7$ & $82 \pm 3$ & $29 \pm 1$ & 51 \\
2 & 1.1 & 0.01 & $8.6 \pm 0.6$ & $70 \pm 2$ & $27 \pm 1$ & 49 \\
3 & 1.1 & 0.01 & $13.9 \pm 2.0$ & $127 \pm 4$ & $22 \pm 1$ & 44 \\
\hline
\end{tabular}

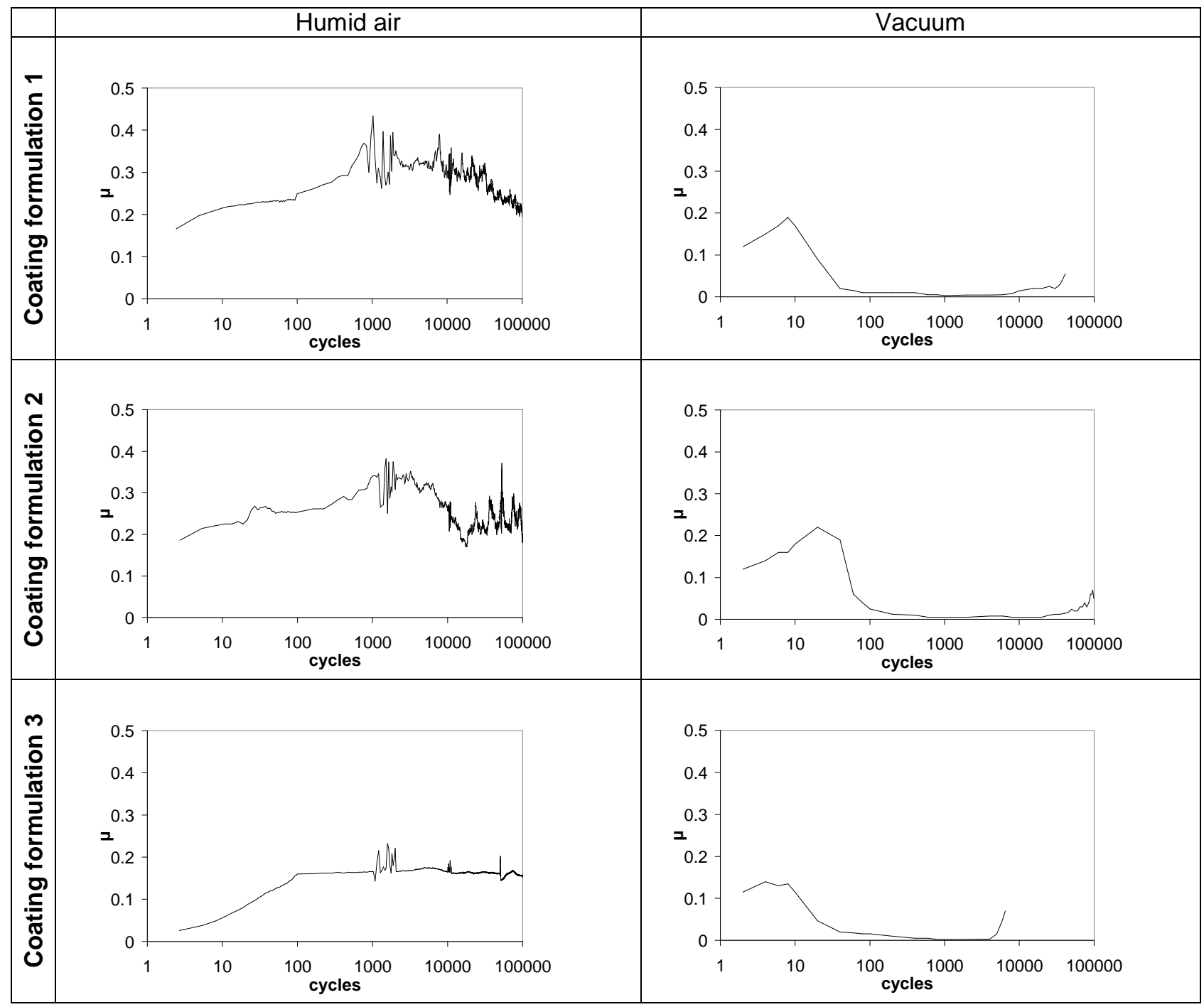

Fig. 1. Mean coefficient of friction versus sliding cycles for the three coating formulations in air and vacuum. 
Coating formulation 3 shows a stable friction level around 0.17 throughout the test. A steady state friction level was reached after 40 000, 10000 and 1000 cycles for coating formulation 1, 2 and 3, respectively. For all three coating formulations, wear track depth never exceeded $0.6 \mu \mathrm{m}$, which constitutes about half the total coating thickness.

For the vacuum tests, the lifetime of the three tested coatings appeared to be lower than in air. For coating formulations 1 and 3 high peak friction values $(\mu \geq 0.3)$ were registered (not shown in Fig. 1 where only mean friction values are provided) which were understood as local coating failures. Vacuum tests for all of the coatings were characterised by a an initial running-in period (> 100 cycles) in which the friction increases to values around 0.2 and then decreases to values around 0.02. The running-in period is followed by a stable period of ultralow mean friction around 0.009 for coating formulations 1 and 3 and 0.007 for coating formulation 2 (reaching a minimum value of around 0.002 for coating formulation 3 ). The running-in period is believed to be attributed to the build-up of a transfer layer on the ball counterface.

SEM post-test inspection of the specimens tested in vacuum (Fig. 2) showed that in all cases the coating had been worn through to the underlying steel substrates at several points within the wear track and layers of very fine wear debris had accumulated on each side of the wear track. EDAX inspection revealed the evidence of areas with high carbon and silicon content on the worn surface of the balls, confirming the transfer of material from the DLC coating. It is believed that this transfer layer provides protection against wear, and decreases the friction in the ball-disc sliding contact. This argument is consistent with other published studies [7] [8], which have demonstrated the transferred materials to be hydrocarbons from the rubbed film.

In vacuum, coating type 2 yielded the best friction and wear results. A very low friction coefficient (0.007) is combined with a long lifetime (100 000 cycles). Because the coating performance in vacuum is crucial for space applications, coating formulation 2 was selected for detailed tribological assessment.

\subsubsection{Effect of environment and load on selected coating formulation}

Coating formulation 2 was selected for detailed testing in air, dry nitrogen and vacuum. Normal loads of 3.3, 5, 10 and $20 \mathrm{~N}$ respectively were applied. Figure 3 shows the evolution of the friction coefficient for this coating type at a normal load of $10 \mathrm{~N}$; it reveals the

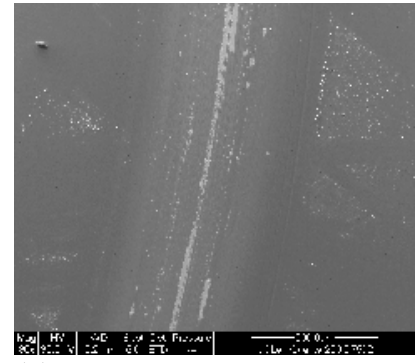

(a)

Fig. 2. SEM images of: (a) wear track on the disc and (b) wear spot on the bal, after the ball-ondisc test in vacuum of coating formulation 2.

major effect of the test environment on the frictional behaviour of the coating. Highly scattered frictional behaviour was obtained in humid air, typically yielding values of 0.20 to 0.25 . In nitrogen, the friction coefficients showed initial values around 0.2 and then reached stable and low values around 0.03. Ultra low friction coefficient values around 0.008 were obtained in vacuum after a running-in period. Friction results are consistent with previous research on DLC coatings [7] [9] and showed an improvement with respect to sputtered $\mathrm{MoS}_{2}$, for which the friction coefficient in vacuum is typically in the range 0.01-0.06 [10]. Coating lifetime exceeded over 100000 cycles in air and dry nitrogen, while in vacuum the coating lifetime was 34000 cycles.

Friction and wear behaviour as function of load and environment are summarized in Figure 4, clearly indicating that both friction and wear are predominantly influenced by the test environment, with the applied normal load providing secondary effects.

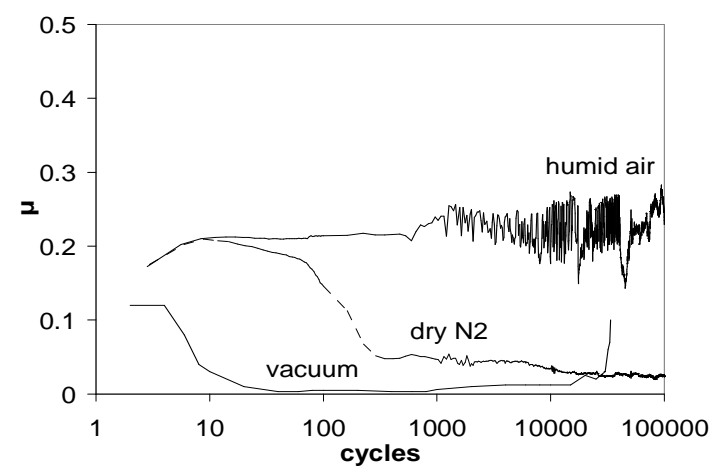

Fig. 3. Tribotest at $10 \mathrm{~N}$ in humid air, dry nitrogen and vacuum for coating formulation 2.

As shown in Figure $4 \mathrm{~b}$, the specific disk wear rate $\left(\mathrm{k}_{\mathrm{v}}\right)$ was relatively low $\left(<1 \times 10^{-5} \mathrm{~mm}^{3} \mathrm{~N}^{-1} \mathrm{~m}^{-1}\right)$ under all test conditions. The specific wear rate in air was at least one order of magnitude higher than the wear rate in $\mathrm{N}_{2}$ 
and lower than the wear rate in vacuum. Post-test microscopic investigation of both the coated discs and balls revealed that the amount of wear debris accumulated near the respective wear scars increased with increasing the normal load for all test environments.

Coating lifetime is affected by the applied load for vacuum tests, yielding lifetimes of 51500, 67000, 34000 and 16500 cycles for 3.3, 5, 10 and $20 \mathrm{~N}$ loads respectively. As a comparison, when tested in vacuum under reciprocating motion at a load of $20 \mathrm{~N}$, sputtered $\mathrm{MoS}_{2}$ is capable of yielding a life in the order of 100000 cycles in comparison with the 16000 cycles observed for the tested DLC coating [11].
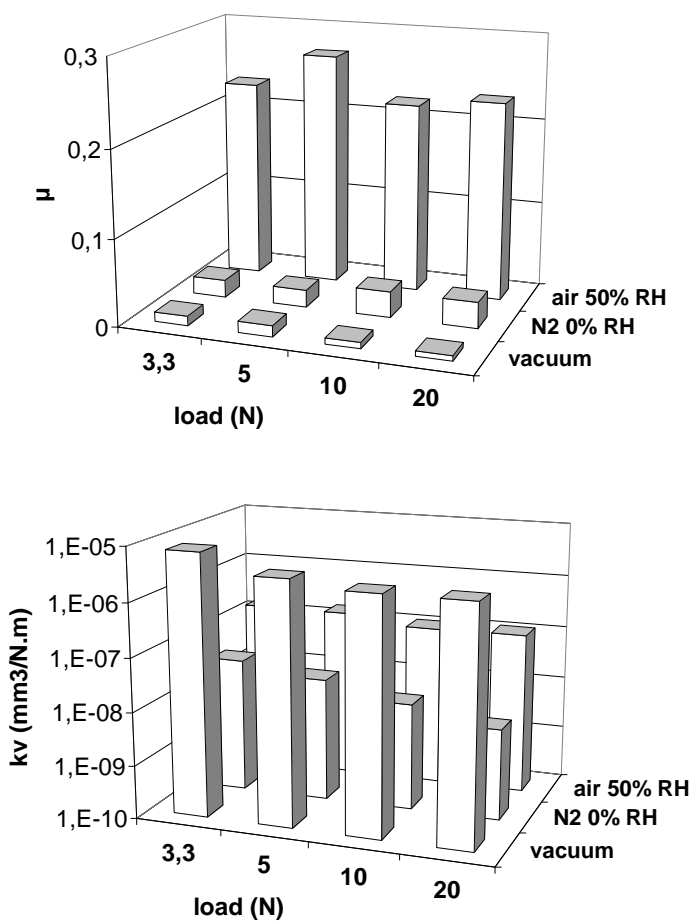

Fig. 4. Effect of load on (a) friction and (b) wear behaviour in air, nitrogen and vacuum.

In general, coating formulation 2 showed good overall performance in humid air, dry nitrogen and vacuum environments. The tribological tests were considered successful with respect to the lubricating qualities of the coating in vacuum, nitrogen or air since the coating, after running-in, exhibited a friction level which did not exceed a mean value of 0.27 for over 100000 cycles. In addition, following test completion, the coatings showed no evidence of delamination or cracking. These results indicated that this DLC coating might be suitable for space applications in general.

\section{CONCLUSION}

The fully PACVD-based Inductively Coupled Plasma (ICP) technique has proven to have potential for the deposition of highly hydrogenated DLC coatings on AISI 52100 steel substrates and ball bearings for use in space. In this paper, three formulations of DLC coatings have been developed for tribological evaluation in air and vacuum.

Ball-on-disc tests have shown that the tribological performance of highly hydrogenated DLC coatings depends strongly on the deposition conditions and the tribotest environment. Coating formulation 2 showed an excellent tribological performance in vacuum, combining a lifetime of 100000 cycles with a very low coefficient of friction ( 0.007 in steady-state regime). Based on these results, this formulation was selected for extended tribological testing in humid air, dry nitrogen and vacuum.

During the extended study, it was found that the test environment has the most decisive effect on both friction and wear rate, while these parameters are only slightly affected by varying the applied load under a given atmosphere. It was concluded that some highly hydrogenated DLC coatings were capable of yielding ultra-low friction values in vacuum $(\mu=0.008)$. The average friction coefficient range obtained in humid air, dry nitrogen and vacuum for the range of applied loads were respectively 0.22 to $0.27,0.02$ to 0.03 , and 0.007 to 0.013 . Coating lifetime was over 100000 cycles for the entire load range tested in air and nitrogen, but was affected by the applied load as far as tests in vacuum are considered. The specific wear rate was lower than $1 \times 10^{-5} \mathrm{~mm}^{3} \mathrm{~N}^{-1} \mathrm{~m}^{-1}$ under all test conditions, which was considered favourable.

\section{ACKNOWLEDGEMENTS}

This work has been funded by ESA/ESTEC General Support Technology Programme (GSTP), under contract No. 16143/02/NL/PA. The authors gratefully acknowledge this support. We are greatly indebted to L. Eersels and D. Havermans for their assistance in coating deposition and characterisation.

\section{REFERENCES}

1. A. Grill, Diamond and Related Materials 8 (1999) 428-434.

2. C. Donnet, A. Grill, Surf. Coat. Technol. 94/95 (1997) 456-462.

3. A. Erdemir, Journal of the I. Mech. E. Part J 216 (2000) 387-400. 
4. K. Vercammen, H. Haefke, Y. Gerbig, A. Vanhulsel, E. Pfluger, J. Meneve, Surf. and Coat. Technol. 133-134 (2000) 466-472.

5. A. Vanhulsel, J.P. Celis, E. Dekempeneer, J. Meneve, J. Smeets, K. Vercammen, Diamond and Related Materials 8 (1999) 1193-1197.

6. N. M. Jennett, A. S. Maxwell, K. Lawrence, L. N. McCartney, R. Hunt, J. Koskinen, T. Muukkonen, F. Rossi, J. Meneve, W. Wegener et al. "Determination of Hardness and Modulus of Thin Films and Coatings by Nanoindentation", NPL report MATC (A) 24 (2001).

7. A. Erdemir, O. L. Eryilmaz, G. Fenske, J. Vac. Sci. Technol. 18 (2000) 1987-1992.

8. A. Erdemir, C. Donnet, Modern Tribology Handbook Vol. 2 (2001) B. Bhusham, ed. CRC Press LLC. 871-908

9. A. Erdemir, O. L. Eryilmaz, I. B. Nilufer, G. Fenske, Diamond and Related Materials 9 (2000) 1987-1992.

10. E. W. Roberts, Space Tribology Handbook (2002). Section 4.2.3, 3rd edition. AEA Technology plc, ESTL.

11. E. W. Roberts, Thin Solid Films 181 (1989) 461473. 